\title{
Stress echocardiography for assessing myocardial ischaemia and viable myocardium
}

\author{
Roxy Senior, Antoinette Kenny, Petros Nihoyannopoulos
}

Northwick Park and St Mark's Hospital, Harrow, Middlesex, UK R Senior

Freeman Hospital, Newcastle, UK A Kenny

Hammersmith Hospital, London, UK P Nihoyannopoulos Correspondence to: Dr Senior, Consultant Dr Senior, Consultant \& St Mark's NHS Trust, Watford Road, Harrow, Middlesex, UK.

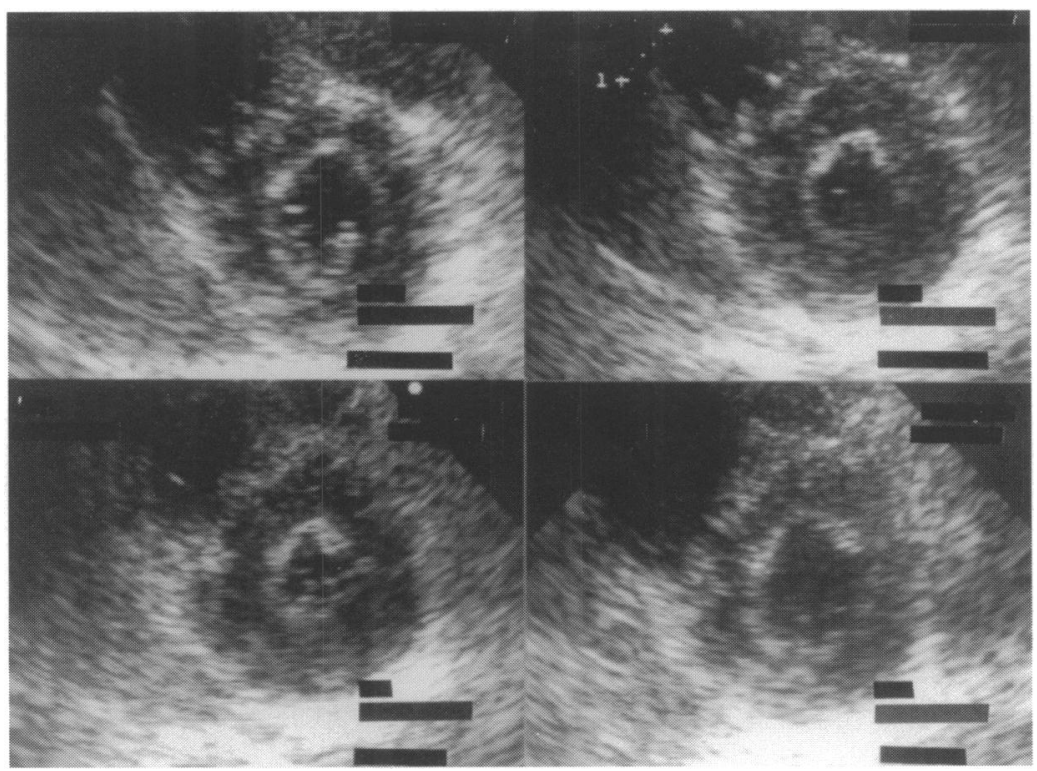

Figure 1 Digitised quad screen display of normal dobutamine stress echocardiography. All images are obtained in short axis at end systole. (Upper left) rest, (upper right) during low dose of dobutamine, (lower left) high dose dobutamine, (lower right) recovery. Note the progressive increase in myocardial thickening with marked reduction in cardiac volumes. This patient had normal coronary arteries.
The electrocardiographic (ECG) ST segment response to exercise is perhaps the most commonly used functional test for the assessment of coronary artery disease. ${ }^{1}$ However, it has important limitations in the evaluation of myocardial ischaemia for two reasons. First, according to the theory of the ischaemic cascade, ECG changes and symptoms are preceded by flow heterogeneity followed by the development of regional myocardial dysfunction. ${ }^{2}$ Thus, unless the patient exercises to the level at which ECG changes occur, demand driven myocardial ischaemia may not occur. Second, resting ECG abnormalities may render changes occurring during stress uninterpretable. Furthermore, the presence of systemic hypertension, even in absence of any resting ECG abnormalities, may result in a false positive diagnosis of coronary artery disease. ${ }^{3}$ In a recent study ${ }^{4}$ only $35 \%$ of 1814 consecutive patients referred for stress testing had an interpretable ECG and a successful maximal exercise.

Echocardiography is currently the most widely used technique for the assessment of structure and function of the heart. Occurrence of abnormal regional systolic wall thickening during stress is perhaps the most specific sign of myocardial ischaemia. ${ }^{2}$ Echocardiography has been used during stress to assess the occurrence of myocardial ischaemia since the late 1970 s. It was not until the advent of modern $90^{\circ}$ scanners, however, together with the development of digital frame grabbing devices, that stress echocardiography became a practical diagnostic tool. Data analysis may be performed off line by review of recorded images from videotapes. This method requires that each view be recorded for a relatively long period and does not allow side by side comparison of resting versus peak stress images. In addition, respiratory artefacts, especially during dynamic exercise and translation motion of the heart during rapid heart rate, make interpretation very difficult. Recent stress echocardiographic studies have used digital acquisition techniques that enable a high quality cardiac cycle from each image plane to be digitised and stored in a continuous loop format. The digitised recording of rest and stress images can then be simultaneously displayed in a quad screen format for analysis. Thus, the combination of improved transducer technology and digital methodologies have resulted in obtaining diagnostic images by most echocardiography laboratories in $90-100 \%$ of patients. ${ }^{5-10}$

Definition of abnormal response to stress A normal response to stress on echocardiography consists of an increase in systolic wall thickening and a reduction in cardiac volume (fig 1). During ischaemia, the systolic wall thickening is reduced in the ischaemic region with or without an overall increase in cardiac volume (fig 2). Failure to observe an increase in systolic wall thickening during stress, however, should not necessarily be regarded as a marker of ischaemia. Crouse et al correlated exercise echocardiography with coronary angiography in 228 patients. ${ }^{6}$ Systolic wall thickening was classified as normal only if the segment showed increased thickening after exercise. This resulted in a high sensitivity $(97 \%)$ and an unacceptably low specificity (64\%) for the detection of coronary artery disease. Failure to increase systolic wall thickening is not specific for coronary artery disease as it can also occur in cardiomyopathy, hypertensive heart disease, $\beta$ blocker therapy, and a low workload. In the presence of abnormal resting systolic wall thickening, worsening systolic thickening is also a marker of myocardial ischaemia.

Several authors have suggested that stress echocardiography may fail to identify 


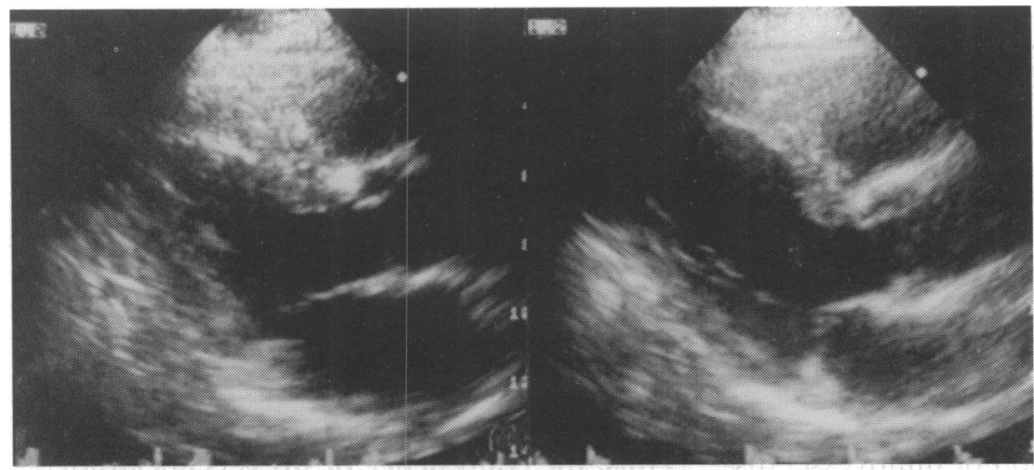

Figure 2 Exercise echocardiography obtained in the parasternal long axis views at end systole at (left) rest and (right) post-exercise. Note the normal septal and posterior wall thickening at rest with marked reduction in systolic thickening of both these walls during peak exercise. Coronary arteriography revealed severe proximal left anterior descending and right coronary artery disease.

inducible ischaemia in regions of resting akinesia because of previous myocardial infarction, and that radionuclide perfusion techniques may be superior to echocardiography for detecting ischaemia in such patients. ${ }^{811}$ Pierard et al ${ }^{12}$ observed that some of these infarcted segments showed an early improvement at low dose dobutamine followed by late deterioration at peak dose during dobutamine stress. These segments were mostly subtended by critically stenosed infarct related artery. In a recent study, ${ }^{13}$ it was observed that the presence or absence of this biphasic response (fig 3) closely agreed with the presence or absence of reversible perfusion defects (radionuclide marker of ischaemia) in regions of severe resting dysynergy. Thus, identification of biphasic response during dobutamine stress testing may enhance the detection of myocardial ischaemia in regions with severe resting myocardial dysfunction.

\section{Methods of stress echocardiography}

EXERCISE ECHOCARDIOGRAPHY

Most studies employing exercise echocardiography have used treadmill or bicycle exercise. Each form of exercise has its advantages and disadvantages when used in conjunction with echocardiography. The advantage of treadmill exercise is that it is widely used, it is the most standardised and readily accepted by patients. However, when treadmill exercise is used, imaging is only performed before and immediately after exercise because of the difficulties in imaging in the upright position. The use of immediately post-exercise imaging is based on observations that exercise induced regional myocardial dysfunction persists between one and five minutes after exercise, and may persist longer in patients with multivessel disease. ${ }^{14-16}$ Nevertheless, image acquisition must be completed within 90 to 120 seconds following termination of exercise for optimal diagnostic accuracy. ${ }^{1718}$ Supine bicycle exercise has the potential advantage of continuous imaging, this is off set by more limited imaging windows during exercise and the technique is less patient friendly.

\section{PHARMACOLOGICAL STRESS}

ECHOCARDIOGRAPHY

The fact that approximately $42 \%$ of patients referred for exercise testing are unable to exercise adequately ${ }^{4}$ together with the ability of obtaining good quality serial echocardiographic images throughout the infusion has resulted in the widespread use of pharmacological stress echocardiography. The prevailing and most widely used drugs are dobutamine and arbutamine. These are catecholamine derivatives that provoke ischaemia by increasing myocardial oxygen demand through raising heart rate, blood pressure, and contractility, mimicking the haemodynamic response of exercise. During dobutamine infusion, atropine is frequently required to achieve target heart rate as dobutamine has a weak chronotropic effect. ${ }^{19} 20$ Arbutamine, which exhibits more balanced chronotropic and inotropic effects, better mimics exercise haemodynamics. ${ }^{21}$ Vasodilator stress using dipyridamole or adenosine are less potent than inotropic agents in provoking abnormal wall thickening, and hence have lower sensitivity for the detection of coronary artery disease..$^{22}$

\section{Accuracy of stress echocardiography}

Accuracy of the varieties of stress echocardiography has been established in numerous laboratories. ${ }^{6-9} 2324$ Using modern equipment, the sensitivity for detection of patients with coronary artery disease varies from $85 \%$ to $96 \%$ with specificity ranging from $78 \%$ to $95 \%$ (table). As with any technique in which a human observer element exists, the sensitivity and specificity tend to be inversely correlated.

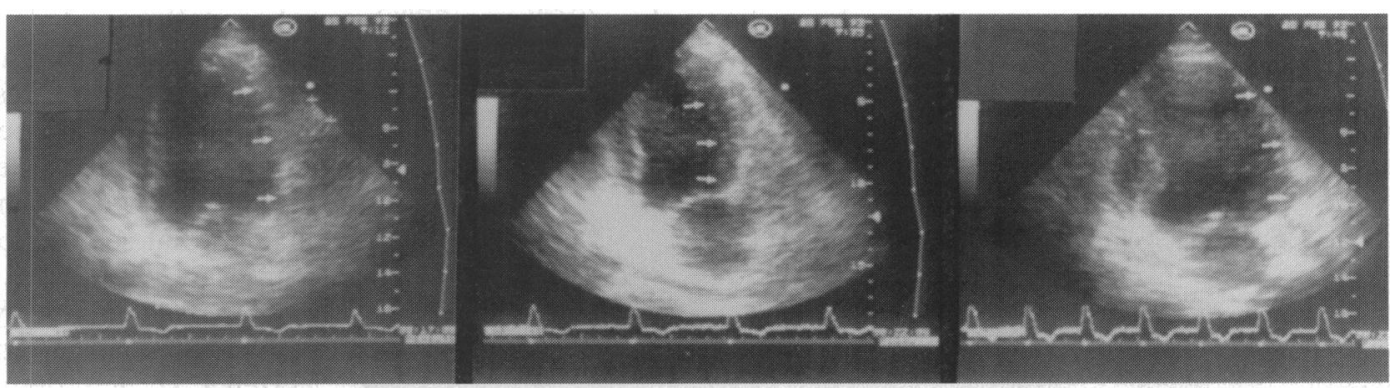

Figure 3 Dobutamine echocardiographic images obtained in the two-chamber view at end systole. (Left) There is severe hypokinesia of the inferior and anterior walls (arrows) before dobutamine infusions. (Middle) There is marked improvement in wall thickening of the anterior wall during low dose dobutamine administration. (Right) At peak dose, the anterior wall becomes severely hypokinetic. Thus, the biphasic response in the anterior wall suggests ischaemia whereas consideration of only the basal (left) and peak dobutamine images (right) suggests that the anterior wall is infarcted. (Senior et al. ${ }^{13}$ ) 
Accuracy of stress echocardiography for detection of coronary artery disease

\begin{tabular}{|c|c|c|c|c|c|c|c|c|c|c|c|}
\hline \multirow[b]{2}{*}{ Author } & \multirow[b]{2}{*}{ Year } & \multirow{2}{*}{$\begin{array}{l}\text { Stress } \\
\text { type }\end{array}$} & \multirow{2}{*}{$\begin{array}{l}\text { Total No. } \\
\text { patients }\end{array}$} & \multicolumn{3}{|c|}{ Sensitivity } & \multirow[b]{2}{*}{ Specificity } & \multirow{2}{*}{$\begin{array}{l}\text { No } \\
M I\end{array}$} & \multicolumn{3}{|c|}{ Sensitivity } \\
\hline & & & & All & $s V$ & $M V$ & & & All & $S V$ & $M V$ \\
\hline $\begin{array}{l}\text { Crouse }^{6} \\
\text { Marwick }^{7} \\
\text { Quinones }^{8} \\
\text { Marwick }^{22} \\
\text { Marcovitz }^{24} \\
\text { Senior }^{10} \\
\text { Ryan }^{9}\end{array}$ & $\begin{array}{l}1991 \\
1992 \\
1992 \\
1993 \\
1992 \\
1994 \\
1993\end{array}$ & $\begin{array}{l}\text { TME } \\
\text { TME } \\
\text { TME } \\
\text { Dob } \\
\text { Dob } \\
\text { Dob } \\
\text { UB }\end{array}$ & $\begin{array}{r}97 \\
179 \\
112 \\
97 \\
141 \\
61 \\
309\end{array}$ & $\begin{array}{l}92 \% \\
84 \% \\
75 \% \\
85 \% \\
95 \% \\
93 \% \\
91 \%\end{array}$ & $\begin{array}{r}100 \% \\
\mathbf{7 7 \%} \\
\mathbf{5 8 \%} \\
\mathbf{8 4 \%} \\
\mathbf{9 5 \%}\end{array}$ & $\begin{array}{l}64 \% \\
93 \% \\
89 \% \\
86 \% \\
97 \%\end{array}$ & $\begin{array}{l}89 \% \\
88 \% \\
82 \% \\
66 \% \\
94 \% \\
78 \%\end{array}$ & 53 & $\begin{array}{l}87 \% \\
83 \%\end{array}$ & $68 \%$ & $96 \%$ \\
\hline
\end{tabular}

TME, treadmill exercise; Dob, dobutamine; UB, upright bicycle; SV, single vessel disease; MV, multivessel disease; MI, myocardial infarction.

Sensitivity for the detection of multivessel disease is higher than for single vessel disease. Likewise, the ability to detect all separate lesions in an individual with multivessel disease is low, as is the case for other imaging modalities because the tests are often stopped for a clinical end point so that only the most severe lesions are unmasked. However, cardiac dilatation during stress indicates the presence of extensive coronary artery disease (fig 4). ${ }^{25}$

\section{Comparison with radionuclide perfusion imaging}

Tomographic imaging (SPECT) has improved the sensitivity of myocardial perfusion for the detection of reversible defects from $85 \%$ with planar techniques to around $95 \%$. Myocardial perfusion SPECT is probably the most widely used non-invasive test for the assessment of coronary artery disease. The detection of reversible defects using perfusion scintigraphy is based on flow heterogeneity during peak stress. Conversely, echocardiography relies on the appearance of wall thickening abnormalities for the diagnosis of ischaemia. While flow heterogeneity appears slightly earlier compared with myocardial dysfunction during ischaemia, echocardiography is more specific for detection of ischaemia. Thus, while perfusion scintigraphy may be more sensitive for the detection of ischaemia, echocardiography is more specific. Eleven studies involving 808 patients using simultaneous stress echocardiography and perfusion scintigraphy have been reported to date. ${ }^{26}$ These used a variety of stress modalities-for example, pharmacological, bicycle, and treadmill exercise. Although cumulative sensitivity of perfusion scintigraphy was marginally superior to echocardiography $(83 \% v 78 \%)$, the difference was not significant, while the cumulative specificity favoured echocardiography $(86 \%$ v $77 \%)$.

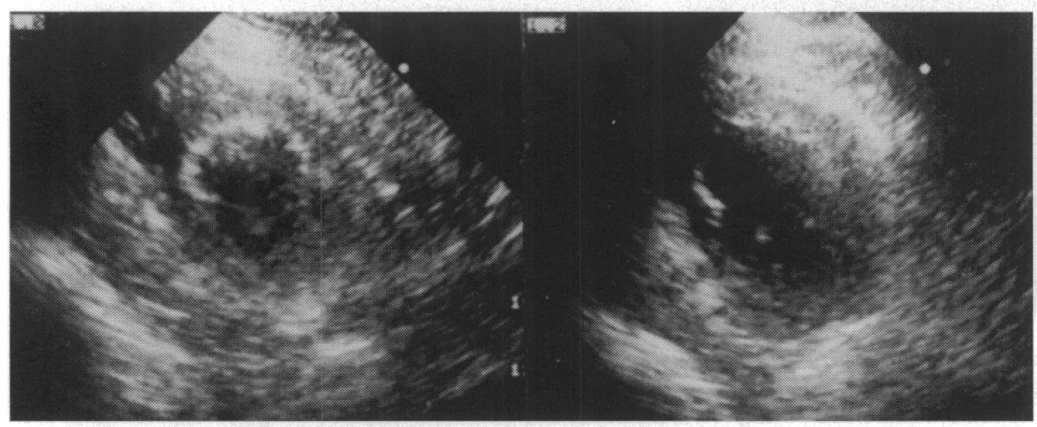

Figure 4 Profound dilatation of left ventricle immediately post-exercise (right). This patient had severe three vessel disease.
Thus, the equivalence of stress echocardiography and perfusion scintigraphy is at variance from the ischaemic cascade model.

This apparent paradox lies in the fact that the relative accuracy of each modality is dependent on imaging characteristics as well as physiology. The development of dysfunction after perfusion abnormalities may be compensated by better spatial resolution and the ability to define wall motion independently in each segment (as opposed to comparison of relative flow used in perfusion imaging). Moreover, abnormal wall thickening resulting from subendocardial ischaemia may be evident before malperfusion is sufficient to be seen by scintigraphy. Conversely, wall thickening abnormality may falsely occur when the heart rate is over 150 beats $/ \mathrm{min} .{ }^{27}$ The status of myocardial perfusion as assessed by SPECT in conjunction with myocardial contraction assessed by echocardiography may be the optimal way of assessing patients with coronary artery disease. We have demonstrated a synergistic value of combining the results of simultaneously performed stress echocardiography and scinitigraphy for predicting coronary artery disease, multivessel disease, and disease in individual coronary arteries..$^{10}$ It is possible that in future, myocardial perfusion could also be assessed during echocardiography with intravenous contrast injection. ${ }^{28}$

In a recent study ${ }^{28}$ it was demonstrated that myocardial contrast echocardiography had a high concordance with scintigraphy for the detection of normal perfusion and irreversible or reversible defects. This would make stress echocardiography an even more powerful modality in assessing the functional significance of coronary artery stenosis.

\section{Prognostic value of stress echocardiography}

It is imperative that a test be able to provide not only diagnostic results but also prognostic information. The one to two year prognosis following a normal exercise or dobutamine stress echocardiography is excellent and equivalent to that seen following normal ${ }^{201}$ thallium scintigraphy. ${ }^{29} 30$ Hard event rates of $0.85 \%$ to $1.5 \%$ per patient per year have been reported following normal stress echocardiography. Mazeika et $a l^{31}$ demonstrated that patients with inducible ischaemia during dobutamine stress have a significantly higher incidence of myocardial infarction compared with those without demonstrable ischaemia. This was further borne out in a larger group of patients 


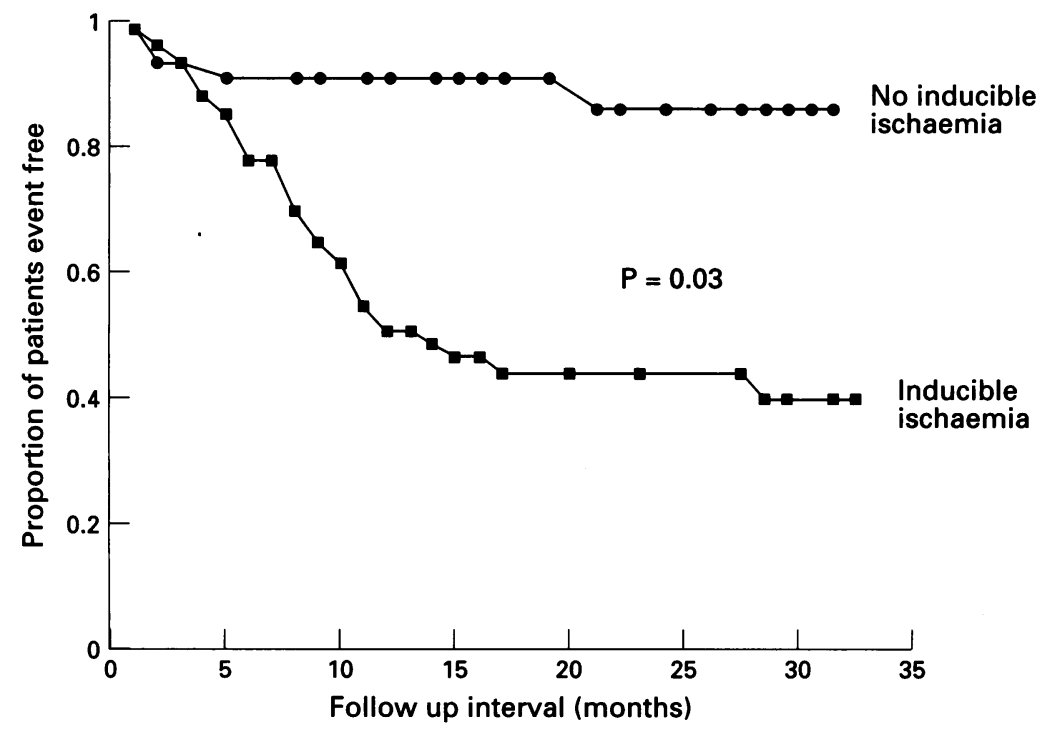

Figure 5 Event free survival curve analysis showed a clear separation between patients with and without inducible ischaemia during dobutamine stress.

with suspected coronary artery disease where inducible ischaemia was found to be a powerful predictor of cardiac events over and above the results of coronary arteriography (fig 5 )..$^{32}$ In a head-to-head comparison between simultaneously performed dobutamine echocardiography and perfusion scintigraphy in a similar group of patients the strongest independent predictors of future cardiac events were wall motion score index at peak stress on echocardiography and extent of perfusion defect. ${ }^{33}$ There are several studies establishing the prognostic value of stress echocardiography following acute myocardial infarction and in patients undergoing major vascular or other non-cardiac surgical procedures. ${ }^{34-38}$

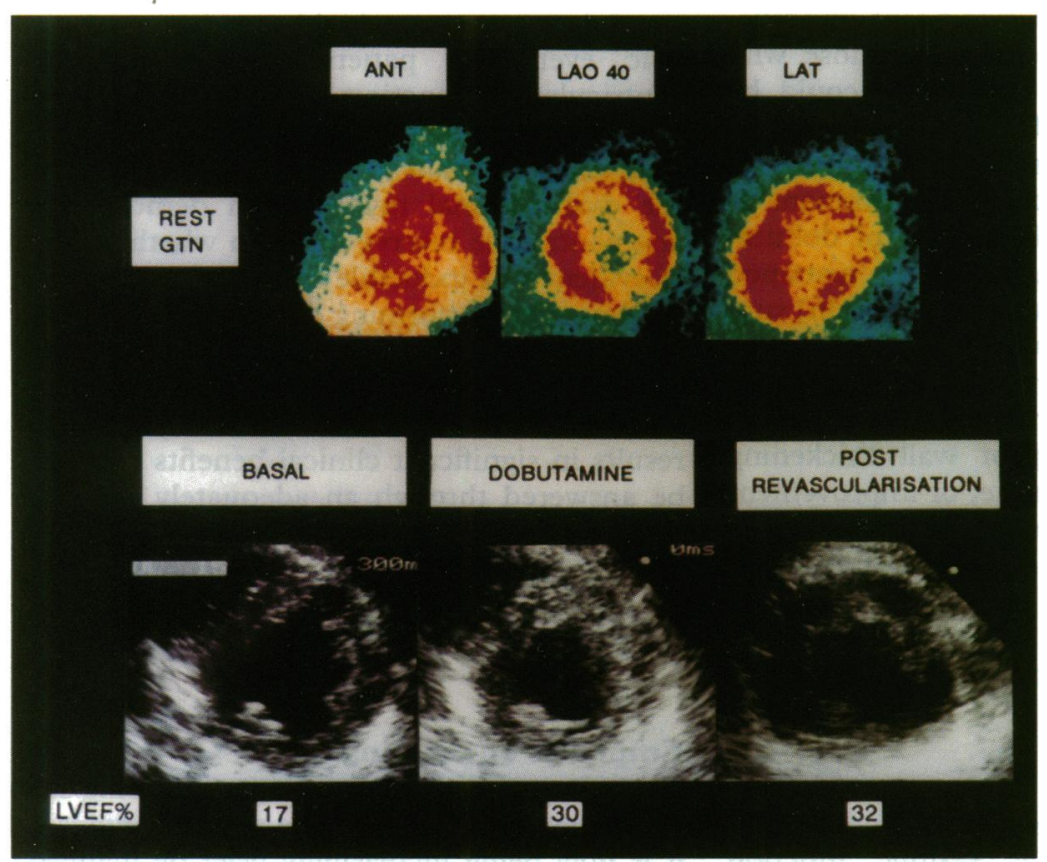

Figure $6{ }^{201}$ Thallium scintigraphy (top) and dobutamine stress echocardiographic images (bottom) demonstrating marked improvement of the regional and overall ventricular function after revascularisation. GTN, glyceryl trinitrate; $A N T$, anterior view; LAO 40, left anterior oblique view $40^{\circ} ; L A T$, lateral view; $L V E F$, left ventricular ejection fraction.
Assessment of viable myocardium

It is important to recognise the presence of viable myocardium when resting myocardial dysfunction is present because of the potential for recovery of function following revascularisation. Several studies in patients following acute myocardial infarction ${ }^{39-41}$ and in chronic heart failure secondary to coronary artery disease $^{42-45}$ have demonstrated that revascularisation of dysfunctional but viable myocardium improves both regional and global left ventricular function. It also improves the functional status in patients with heart failure, potentially improving survival and reducing the need for cardiac transplantation. ${ }^{45}$ Observational studies indicate that patients with non-revascularised dysfunctional but viable myocardium may be worse off than those with revascularised myocardium. ${ }^{4647}$ It is conceivable that assessment of left ventricular systolic function at rest may underestimate the presence of viability. Most left ventricular wall thickening occurs as a result of subendocardial motion while the contribution of the subepicardium is minimal ${ }^{48}$ Increased myocardial thickening of the middle and outer myocardial layers following catecholamine stimulation ${ }^{49} 50$ contributes to overall wall thickening during exercise without necessarily indicating improved subendocardial function. Conversely, lack of improvement of systolic function following revascularisation may result from inadequate revascularisation, the presence of comorbid conditions such as hypertensive heart disease and diabetes mellitus, or lack of sufficient viable cells that can trigger contraction. However, the basic characteristics of viable myocardium are that it is metabolically functional (detected by PET), has a permeable cell membrane (detected by ${ }^{201}$ thallium or sestamibi uptake), that it is responsive to catecholamine (detected by dobutamine stimulation during echocardiography or magnetic resonance imaging), and that the microcirculation is present (seen with myocardial contrast echocardiography).

\section{Acute myocardial infarction}

In the thrombolytic era, the important question following acute myocardial infarction is whether the dysfunctional myocardium in the infarct zone is viable and, if so, whether it is subtended by significantly stenosed artery. Dobutamine echocardiography has the potential to answer these questions. If an infarct related artery is not significantly narrowed, the improvement in wall thickening during dobutamine infusion will be inversely related to infarct size. ${ }^{49}$ If the infarct is small, $5 \mu \mathrm{g} / \mathrm{kg} /$ min of dobutamine is usually adequate to trigger wall thickening. Higher doses will be required in larger infarcts, but doses higher than $15 \mu \mathrm{g} / \mathrm{kg} / \mathrm{min}$ are rarely necessary. ${ }^{49}$ Deterioration of wall thickening is also a sign of viable myocardium as ischaemia cannot occur in necrosed tissue. Thus, it is not surprising that Smart et $a l^{39}$ showed that the greatest sensitivity for predicting spontaneous improvement of resting wall thickening follow- 
Figure 7 Left ventricular ejection fraction (LVEF) at rest (Pre) and after revascularisation (Post) in patients with improved wall thickening in two or more contiguous segments as demonstrated by dobutamine echocardiography. (Senior et al. ${ }^{45}$ )

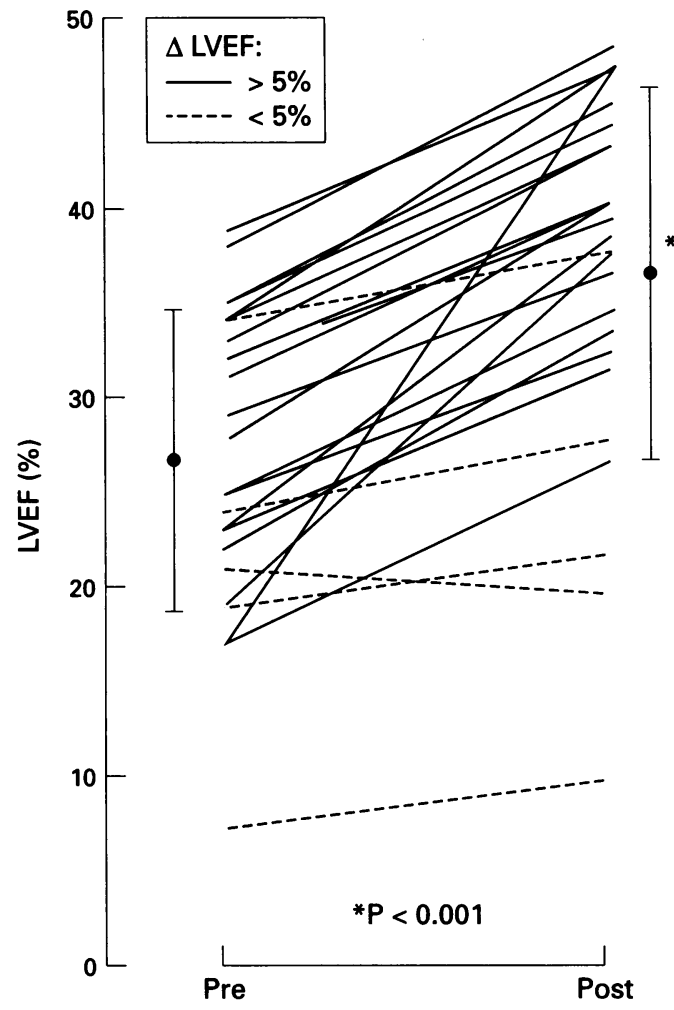

ing acute myocardial infarction was with low dose dobutamine $(4 \mu \mathrm{g} / \mathrm{kg} / \mathrm{min})$ because patients with small infarcts are more likely to show spontaneous regional recovery than those with larger infarcts. Similarly, in another study, ${ }^{41}$ only half the patients in the group showing improvement in wall thickening at a dobutamine dose of $10 \mu \mathrm{g} / \mathrm{kg} / \mathrm{min}$ showed spontaneous improvement in regional function, while all patients showed viable myocardium by PET. Larger infarction may not show spontaneous recovery in function despite presence of contractile reserve. Barilla et $a^{40}$ demonstrated that patients undergoing revascularisation showed significant improvement in function compared with those who had medical treatment, and these could be prospectively predicted by dobutamine stress echocardiography. Thus, in the setting of acute myocardial infarction, improvement of wall thickening during low doses of dobutamine $\quad(5-15 \mu \mathrm{g} / \mathrm{kg} / \mathrm{min})$ with sustained improvement at peak dose $(40 \mu \mathrm{g} / \mathrm{kg} / \mathrm{min})$ suggests stunned myocardium subtended by an open infarct related artery, and suggests that it is likely to recover spontaneously over time. Alternatively, worsening of wall thickening during low dose dobutamine, or improvement during low dose followed by deterioration at high dose dobutamine, suggest that the dysfunctional myocardium is viable but is subtended by a critically stenosed artery and therefore revascularisation will be the treatment of choice.

\section{Chronic coronary artery disease}

Reduced left ventricular systolic function caused by severe chronic coronary artery disease may result from hibernating myocardium $^{51}$ or repetitive stunning subtended by severe stenosis, where resting flow is normal but repeated episodes of mild ischaemia could leave the myocardium perpetually stunned. ${ }^{52}$ In the presence of severe left ventricular dysfunction, demonstration of contractile reserve by low doses of dobutamine is predictive of recovery in both regional and global left ventricular systolic function following revascularisation..$^{43}$ In a study by Baer et al $^{53}$ it was shown that ${ }^{18} \mathrm{~F}$-flurodeoxyglucose uptake on PET in akinetic segments with contractile reserve on dobutamine echocardiography was similar to that in normal segments, whereas akinetic segments with no contractile reserve have significantly lower glucose uptake. In another study, ${ }^{45}$ a high concordance $(81 \%)$ was noted between ${ }^{201}$ thallium uptake (a marker of viable myocardium) and low dose $(5-15 \mu \mathrm{g} / \mathrm{kg} / \mathrm{min})$ dobutamine echocardiography for the detection of viable and non-viable segments (fig 6). In this study, dobutamine echocardiography showed a sensitivity of $87 \%$ and a specificity of $82 \%$ for the recovery of regional function, similar to that of other studies in the same group of patients. Furthermore, using the criterion of improvement of at least one grade in at least two contiguous segments as an indicator of existing contractile reserve, left ventricular ejection fraction improved from $27 \cdot 8 \%$ to $38.9 \%$ ( $P<$ 0.001 ) (fig 7)..$^{45}$

However, it is important to determine whether these viable segments also demonstrate ischaemia at high doses of dobutamine. In a study by Afridi $e t a^{54}$ a biphasic response alone had a specificity of $88 \%$ for the recovery of a segment after revascularisation. Sustained improvement throughout the infusion had a very poor predictive value as it can be seen in cardiomyopathic ventricle from other causes. Williams et al $^{55}$ showed that presence of viable myocardium, as suggested by both presence of contractile reserve and biphasic response during dobutamine, was highly predictive of cardiac events in patients with severe left ventricular dysfunction. Thus, when investigating patients with left ventricular dysfunction, it is important to detect not only whether the dysfunctional myocardium demonstrates any contractile reserve but also whether there is evidence of inducible ischaemia. This may be shown by performing dobutamine echocardiography at both low and high doses during continuous imaging. Whether revascularisation of dysfunctional but viable myocardium results in significant clinical benefits can only be answered through an adequately powered study randomising patients with and without dobutamine responsive dysfunctional myocardium to medical treatment and revascularisation.

\section{Emphasis on training}

The advantage of echocardiography being safe and inexpensive has become a disadvantage as it is now being increasingly used by inappropriately trained people with resultant inaccurate reports. Recently, the British Society of Echocardiography issued guidelines for train- 
ing that are essential for those performing and interpreting echocardiography studies. ${ }^{56}$ This is even more true for stress echocardiography, which should only be conducted by fully trained cardiologists. Because of the radiation hazards, nuclear stress testing is mainly confined to experts, thus containing in someway the irresponsible use of stress testing with radioisotopes. There is no such protective net with stress echocardiography. It is of pivotal importance that individual expertise is increased steadily and cautiously in a protected centre with frequent audits before stress echocardiography is used as a decision making investigation. It is recommended that for a centre to become expert on stress echocardiography it needs to perform at least five stress echocardiographic examinations a week for approximately a year with the appropriate exposure and feedback. To do this, echocardiography laboratories should identify the necessary space in the department, and devote time, equipment, and personnel for regularly performed studies.

1 Chaitman BR. The changing role of the exercise electrocardiogram as a diagnostic and prognostic test for chronic ischemic heart disease. $¥ \mathrm{Am}$ Coll Cardiol 1986;8:1195-210.

2 Nesto RW, Kowalchunck GJ. The ischemic cascade: tem poral response of hemodynamic, electrocardiographic and symptomatic expression of ischemia. Am $\mathcal{f}$ Cardiol 1987;57:23C-30C

3 Senior R, Basu S, Handler C, Raftery EB, Lahiri A Diagnostic accuracy of stress echocardiography for detection of coronary artery disease in hypertensive patients. Eur Heart 7 1996;17:289-95.

4 Marwick TH. Current status of non-invasive techniques for the diagnosis of myocardial ischemia [editorial]. Acta Clin Belg 1992;47:1-5.

5 Hecht HS, Debord L, Shaw R, Chin H, Dunlap R, Ryan $\mathrm{C}$, et al. Supine bicycle stress echocardiography versus tomographic thallium-201 exercise imaging for the detectomographic thallium-201 exercise imaging for the detec1993;6: 177-85.

6 Crouse LF, Harbrecht J, Vacek JL, Rosamond TL, Kramer PH. Exercise echocardiography as a screening test for coronary artery disease and correlation with coronary angiography. Am $\mathcal{F}$ Cardiol 1991;67:1213-18.

7 Marwick TH, Namec JJ, Pashkow FJ, Stewart WJ, Salcedo EE. Accuracy and limitations of exercise echocardiography in routine clinical setting. $\mathcal{F} \mathrm{Am}$ Coll Cardiol 1992; 19:74-81

8 Quinones MA, Verani MS, Haichin RM, Mahmarian JJ, Suarez J, Zoghbi WA. Exercise echocardiography versus $201 \mathrm{Tl}$ single-photon emission computed tomography in evaluation of coronary artery disease analysis of 292 patients. Circulation 1992;85:1026-31

9 Ryan T, Segar DS, Sawada SG, Berkovitz KE, Whang D, Dohan AM, et al. Detection of coronary artery disease with upright bicycle exercise echocardiography. $7 \mathrm{Am} \mathrm{Soc}$ Echocardiogr 1993;6:186-97.

10 Senior R, Sridhara BS, Anagnostou E, Handler C, Raftery $\mathrm{EB}$, Lahiri A, et al. Synergistic value of simultaneous stress dobutamine sestamibi spect and echocardiography in the detection of coronary artery disease. Am Heart $f$ 1994;128:713-18.

11 Pozzoli MM, Fioretti PM, Salustri A, Reijs AE, Roelandt JRTC. Exercise echocardiography and technetium-99m MIBI single-photon emission computed tomography in the detection of coronary artery disease. $\mathrm{Am} F \mathrm{Cardiol}$ 1991;67:350-5.

12 Pierard LA. Pharmacological stress echocardiography. In: Roelandt JRT, ed. Cardiac ultrasound. Edinburgh: Churchill Livingstone, 1993:505-12.

13 Senior A, Lahiri A. Enhanced detection of myocardial ischaemia in patients with wall motion abnormality by utilising the "biphasic" response of stress dobutamine during serial echocardiography. F Am Coll Cardiol 1995; 26:26-32.

14 Wann LS, Faris JV, Childress RM, Dillon JC, Weyman AE, Feigenbaum H. Exercise cross-sectional echocardiography in ischaemic heart disease. Circulation 1979;60: 1300-8.

15 Maurer G, Nanda NC. Two dimensional echocardiography: evaluation of exercise-induced left and right ventricular asyngergy: correlation with thallium scanning. $A m \mathcal{F}$ Cardiol 1981;48:720-7.

16 Robertson WS, Feigenbaum H, Armstrong W, Dillon J, O'Donnell J, McHenry PW. Exercise echocardiography: a clinically practical addition in the evaluation of coroa clinically practical addition in the evaluation of coro-

17 Armstrong WF. Stress echocardiography for detection of coronary artery disease. Circulation 1991;84(Suppl 1): I43.

18 Nihoyannopoulos P, Marsonis A, Joshi J, Athanassopoulos G, Oakley C. Magnitude of myocardial dysfunction is greater in painful than in painless myocardial ischemia: an exercise echocardiographic study. $₹ \mathrm{Am}$ Coll Cardio 1995;25:1507-12.

19 Fioretti PM, Poldermans D, Salustri A, Forster T, Bellotti P, Boersma E, et al. Atropine increases the accuracy of Boersma E, et al. Atropine increases the accuracy of
dobutamine stress echocardiography in patients taking
beta-blockers. Eur Heart $₹$ 1994;15:355-60.

20 McNeill AJ, Fioretti PM, El-Said EM, Salustri A, Forster T, Roelandt TC Jr. Enhanced sensitivity for detection of coronary artery disease by addition of atropine to dobutacoronary artery disease by addition of atropine to dobuta-

21 Young M, Pau W, Weisner J. Characterization of arbutamine: a novel catecholamine stress agent for diagnosis of coronary artery disease. Drug Dev Res 1994;32:19-28

22 Marwick T, Willemart B, D'Hondt AM, Baudhuin T Wijns W, Detry JM, et al. Selection of the optimal nonexercise stress for the evaluation of ischemic regional myocardial dysfunction and malperfusion: comparison of dobutamine and adenosine using echocardiography and Tc-99m MIBI single photon emission computed tomography. Circulation 1993;87:345-54.

23 Sawada SG, Segar DS, Ryan T, Brown SE, Dohan AM, Williams $R$, et al. Echocardiographic detection of coronary artery disease during dobutamine infusion. Circulation 1991;83:1605-14

24 Marcovitz PA, Armstrong WF. Accuracy of dobutamine stress echocardiography in detecting coronary artery disease. Am F Cardiol 1992;69:1269-73.

25 Dagianti A, Penco M, Agati L, Sciomer S, Dagianti A Rosanio S, et al. Stress echocardiography: comparison of exercise, dipyridamole and dobutamine in detecting and predicting the extent of coronary artery disease. $\Im \mathrm{Am} \mathrm{Coll}$ predicting the extent of

26 O'Keefe JH Jr, Barnhart CS, Bateman TM. Comparison of stress echocardiography and stress myocardial perfusion scintigraphy for diagnosing coronary artery disease and assessing its severity. Am f Cardiol 1995;75:25D-34D.

27 Becker B, Vered MD, Bloom NV, Ohad D, Battler A, D Segni E. Decreased thickening of normal myocardium with transient increased wall thickening during stres echocardiography with atrial pacing. $\mathcal{f} A m$ Soc Echocardiogr 1994;7:381-7

28 Senior R, Lahiri A, Raval U, Khattar R, Dittrich H, Kaul S. Detection of coronary artery disease using myocardia contrast echocardiography [abstract]. Circulation 1996; 94:140

29 Sawada SG, Ryan T, Conley MJ, Corya BC, Feigenbaum H, Armstrong WF. Prognostic value of a normal exercise echocardiogram. Am Heart $\mathcal{F}$ 1990;120:49-55.

30 Krivokapich J, Child JS, Gerber RS, Gerber RS, Lem V, Morer D. Prognostic usefulness of positive or negative exercise stress echocardiography for predicting coronary events in ensuing twelve months. Am $f$ Cardiol 1993;71: 646-51.

31 Mazeika PK, Nadazdin A, Oakley C. Prognostic value of dobutamine echocardiography in patients with high pretest likelihood of coronary artery disease. $A m \mathcal{F}$ Cardio 1993; 71:33-9.

32 Senior R, Soman P, Khattar R, Lahiri A. Prognostic value a dobutamine stress echocardiography in patients undergo ing diagnostic coronary arteriography. $\mathrm{Am} \mathcal{F}$ Cardio 1997;79:1610-14.

33 Senior R, Raval U, Soman P, Ray SG, Lahiri A. Prognostic value of stress dobutamine echocardiography and myocardial perfusion imaging in patients with high likelihood for coronary artery disease [abstract]. Eur Heart $\mathcal{F}$ 1995;16:326.

34 Ryan T, Armstrong WE, O'Donnell JA, Feigenbaum $H$ Risk stratification after acute myocardial infarction by means of exercise two-dimensional echocardiography. Am Heart f 1987;114:1305-16.

35 Applegate RJ, Dell'italia LJ, Crawford MH. Usefulness of two-dimensional echocardiography during low-level exercise testing early after uncomplicated myocardial exercise testing early after uncomplicate
infarction. $A m \Im$ Cardiol 1987;60:10-14.

36 Camerieri A, Bianchi F, Landi P, Charanda G, Chiarella F Severso G, et al. Risk stratification with pharmacological stress echocardiography early after uncomplicated myocardial infarction: the impact of revascularization. Circulation 1993;88:I120.

37 Poldermans D, Fioertti PM, Forster T, Thomas IR Boersma E, El-Said. Dobutamine stress echocardiography for assessment of perioperative cardiac risk in patients undergoing major vascular surgery. Circulation 1993;87:1506-12.

38 Lalka SG, Sawada SG, Dalsing MC, Cikrit DF, Sawchuk AP, Kovacs PL, et al. Dobutamine stress echocardiography as a predictor of cardiac events associated with aortic surgery. 7 Vasc Surg 1992;15:831-42.

39 Smart SC, Sawada S, Ryan T, Segar D, Acherton L Berkovitz $\mathrm{K}$, et al. Low dose dobutamine echocardiography detects reversible dysfunction after thrombolytic therapy after acute myocardial infarction. Circulation 1993;88:405-15.

40 Barilla F, Gheorghiade M, Alam M, Khaja F, Goldstein S Low dose dobutamine in patients with acute myocardial infarction identifies viable but not contractile myocardium and predicts the magnitude of improvement in wall motion abnormalities in response to coronary in wall motion abnormalities in response to cor 
41 Pierard L, De Landsheere CM, Berthe C, Rigo P, Kulbertus HE. Identification of viable myocardium by echocardiography during dobutamine infusion in patients with myocardial infarction after thrombolytic therapy: comparison with positron emission tomography. $f \mathrm{Am}$ Coll Cardiol 1990;15:1021-31.

42 Perrone-Dilardi P, Pace L, Prastaro M, Piscione F, Betochcchi S, Squame F, et al. Dobutamine echocardiog raphy predicts improvement of hypoperfused dysfunctional myocardium after revascularization in patients with coronary artery disease. Circulation 1995;92:2556-65.

43 La Canna G, Alfieri O, Giubbibi R, Gargano M, Ferrari R, Visoioli $O$. Echocardiography during infusion of dobutamine for identification of reversible dysfunction in mine for identification of reversible dysfunction in patients with chronic co
Cardiol 1994;23:617-26.

44 Cigarroa CC, deFillipi CR, Brickner E, Alvarez LG, Wait MA, Grayburn PA. Dobutamine stress-echocardiography identifies hibernating myocardium and predicts recovery of left ventricular function after coronary revascularization. Circulation 1993;88:430-6.

45 Senior R, Glenville B, Basu S, Sridhara BS, Anagnostou E, Stanbridge $\mathrm{R}$, et al. Dobutamine echocardiography and thallium-201 imaging predict functional improvement after revascularisation in severe ischaemic left ventricular dysfunction. Br Heart $\mathcal{f}$ 1995; 74:358-64.

46 Lee KS, Marwick TH,Cook SA, Go RT, Fix JS, James KB. Prognosis of patients with left ventricular dysfunction with and without viable myocardium after myocardial infarction: relative efficacy of medical therapy and revascularization. Circulation 1994;90:2687-94.

47 Di Carli MF, Davidson M, Little R, Khanna S, Mody FV, Brunken RC, et al. Value of metabolic imaging with positron emission tomography for evaluating prognosis in patients with coronary artery disease and left ventricular dysfunction. Am ₹ Cardiol 1994;73:527-33.
48 Myers JH, Stirling MC, Choy M, Buda AJ, Gallagher KP. Direct measurement of inner and outer wall thickening dynamics with epicardial echocardiography. Circulation 1986;74:164-72.

49 Sklenar J, Villanueva FS, Glasheen WP, Ismail S, Goodman NC, Kaul S. Dobutamine echocardiography for determining the extent of myocardial salvage after reperfusion: an experimental evaluation. Circulation 1994;90:1503-12.

50 Pirolo JS, Hutchins GM, Moore GW. Infarct expansion: pathologic analysis of 204 patients with a single myocarpathologic analysis of 204 patients with a sin

51 Rahimtoola SH. The hibernating myocardium. Am Heart 1989;117:211-21.

52 Vanoverschelde J, Wijns W, Depre C Essamm B Heyndrickx GR, Borgers M, et al. Mechanisms of chronic regional postischemic dysfunction in humans: chronic regional postischemic dysfunction in humans: new insights from the study of noninfarcted collatera

53 Baer FM, Voth E, Deutsch HJ, Schneider CA, Schicha H, Sechtem U. Assessment of viable myocardium by dobutamine transesophageal echocardiography and comparison with fluorine-18 fluorodeoxyglucose positron emission tomography. 7 Am Coll Cardiol 1994;24:343-53.

54 Alfridi I, Kleiman NS, Raizner AE, Zoghbi WA Dobutamine echocardiography in myocardial hibernation: optimal dose and accuracy in predicting recovery of ventricular function after coronary angioplasty. Circulation 1995;91:663-70.

55 Williams MJ, Odabashian J, Lauer MS, Thomas JD, Marwick TH. Prognostic value of dobutamine echocardiography in patients with left ventricular dysfunction. $\mathcal{F}$ Am Coll Cardiol 1996;27:132-9.

56 Monaghan MJ, Anderson V, Chambers, J, Leech G Martin $M$, Nihoyannopoulos $P$, et al. Training in echocardiography. Br Heart $f$ 1994;71(Suppl):2-5. 
vascular disease, risk factors, interventions, and prognosis, fulfilling criteria for a suitable non-invasive assessment of endothelial function. Furthermore, several groups have targeted this molecule as a means of intervening in the thrombotic process. ${ }^{16}$ The next five years will tell if this approach is successful.

The non-invasive approach outlined by Mullen and colleagues has provided invaluable opportunities to dissect the pharmacology of the endothelium. However, by its very nature such an approach is unlikely to provide epidemiological data or even data to compare groups with large numbers of subjects. We submit that plasma markers such as von Willebrand factor and soluble thrombomodulin are likely candidates for providing data of this nature.

ANDREW BLANN GREGORY LIP

Haemostasis, Thrombosis and Vascular Biology Unit, University Department of Medicine The City Hospital, Dudley Road, Birmingham B18 $7 Q H$, UK

1 Mullen MJ, Thorne SA, Deanfield JE, Jones $\mathrm{CJH}$. Non-invasive assessment of endothelial function. Heart 1997;77:297-8.

2 Lip GYH, Blann AD. Von Willebrand factor and its relevance to cardiovascular disease. Br Heart $\mathcal{f} 1995 ; 74: 580-3$.

3 Blann AD, Taberner DA. A reliable marker of endothelial cell dysfunction: does it exist? $\mathrm{Br}$ f Haematol 1995;90:244-8.

4 Badimon L, Badimon JJ, Chesebro JH, Fuster V. von Willebrand factor and cardiovascula disease. Thromb Haemostas 1993;70:111-18.

5 Greaves M, Pickering C, Knight G, Boulton ALM, Ball J, Ward JD, et al. Changes in the factor VIII complex in diabetic ketoacidosis: evidence of endothelial cell damage? Diabetologia 1987;30:160-5.

6 Van den Berg M, Boers GHJ, Franken DG Blom HJ, van Kamp GJ, Jakobs C, et al. Hyperhomocysteinaemia and endothelial dysfunction in young patients with peripheral arterial occlusive disease. Eur $₹$ Clin Invest 1995;25:176-81.

7 Thompson SG, Kienast J, Pyke SDM, Haverkate F. Hemostatic factors and the risk of myocardial infarction or sudden death in patients with angina pectoris. $N$ Engl $\mathcal{F}$ Med patients with angina

8 Blann AD, Miller JP, McCollum CN. Von Willebrand factor and soluble E-selectin in the prediction of cardiovascular disease progression in hyperlipidaemia. Atherosclerosis

9 Boffa MC. Considering cellular thrombomodulin distribution and its modulating factors can facilitate the use of plasma thrombomodulin as a reliable endothelial marker. modulin as a reliable endothelial masis 1996;26(Suppl 4):233-43.

10 Blann AD, Amiral J, McCollum CN. Circulating endothelial cell/leucocyte adhesion moleing endothelial cell/leucocyte adhesion molecules in ischaemic he

11 Seigneur M, Dufourcq P, Gin H, Delafaye C, Amiral J, Pruvost A, Boisseau MR. Plasma thrombomodulin levels increase with the severity of diabetic retinopathy. Blood Coag Fibrinolys 1994;5:845-6.

12 Blann AD, Amiral J, McCollum CN. Prognostic value of increased soluble thrombomodulin and increased E-selectin in ischaemic heart disease. Eur $\mathcal{f}$ Haem. [In press.]

13 Gearing AJH, Newman W. Circulating adhesion molecules in disease. Immunol Today 1993;14:506-12.

14 Blann AD, Seigneur M, Steiner M, Boisseau MR, McCollum CN. Circulating endothelial cell markers in peripheral vascular disease: cell markers in peripheral vascular disease: atherosclerotic disease. Eur $\mathcal{F}$ Clin Invest. [In press.]

15 Belch JJF, Shaw JW, Kirk G, McLaren M, Robb R, Maple C, Morse P. The white blood cell adhesion molecule E-selectin predicts restenosis in patients with intermittent claudication undergoing percutaneous transluminal angioplasty. Circulation 1997;95: 2027-31.

16 Ruggeri ZM. Inhibition of platelet vessel wall interaction. Platelet receptors, monoclonal antibodies, and synthetic peptides. Circulation 1990;81(Suppl 1):I35-9.

This letter was shown to the authors, who reply as follows.

We read with interest the letter from Drs Blann and Lip regarding the advantages and limitations of plasma markers of endothelial cell function. We share their interest in this area of research and its potential clinical application. We feel, however, that evaluation of nitric oxide mediated arterial physiology in large conduit arteries using the non-invasive techniques described ${ }^{1}$ may provide insight into the pathophysiology of vascular disease, be an early marker of endothelial injury, and a means of evaluating interventions early in the natural history of atherogenesis.

The value of these measures in predicting disease development and outcome is not known and is central to current research efforts. Our published data, however, indicate that this technique can be used to study endothelial function in large groups of subjects from early in childhood, to provide epidemiological data, compare groups of subjects with risk factors, and demonstrate beneficial response to interventions. ${ }^{2-5}$

M J MULLEN M E DEANFIELD

Great Ormond Street Hospital for Children NHS Trust, London WC1N $3 \mathcal{F H}$, UK

1 Celermajer DS, Sorensen KE, Gooch VM, Spiegelhalter DJ, Miller OI, Sullivan ID, $e$ al. Non-invasive detection of endothelial dysfunction in children and adults at risk of atherosclerosis. Lancet 1992;340:1111-15.

2 Leeson CPM, Whincup PH, Cook DG, Donald AE, Papacosta O, Lucas A, et al. Flow mediated dilatation in 9-11 year old children: the influence of intrauterine and childhood factors. Circulation. [In press.]

3 Celermajer DS, Sorensen KE, Bull C, Robinson J, Deanfield JE. Endotheliumdependent dilation in the systemic arteries of asymptomatic subjects relates to coronary asymptomatic subjects relates to coronary
risk factors and their interaction. $f \mathrm{Am} \mathrm{Coll}$ risk factors and their interac
Cardiol 1994;24:1468-74.

4 Sorensen KE, Celermajer DS, Georgakopoulos D, Hatcher G, Betteridge DJ, Deanfield JE. Impairment of endothelium-dependent dilation is an early event in children with familia hypercholesterolemia and is related to the lipoprotein (a) level. $\mathcal{f}$ Clin Invest 1994;93: 50-5.

5 Clarkson P, Adams MR, Powe AJ, Donald AE, McCredie R, Robinson J, et al. Oral L-arginine improves endothelium-dependent dilation in hypercholesterolemic young adults. $f$ Clin Invest 1996;97:1989-94.

\section{CORRECTION}

Pregnancy and congenital heart disease C M Oakley Heart 1997;78:12-14.

The first sentence of the section Atrial septal defects should have read:

"The only frailty of patients with unrepaired atrial septal defects is intolerance of blood loss that can force left to right shunting, to the sudden detriment of left ventricular and coronary flow."

And not as published. The error is regretted. 